\title{
Las colonias en los Episodios galdosianos
}

\author{
The colonies in the Galdosianos' episodes \\ Dolores Troncoso Durán \\ Universidad de Vigo - Vigo, España
}

$\odot$

\begin{abstract}
Resumen: Pese a que Galdós nunca llegó a escribir el programado episodio Las colonias perdidas, la referencia a éstas y su significado para la sociedad española del siglo XIX están presentes a lo largo de los Episodios nacionales como muestra este artículo que además de apuntar su detallada localización en los episodios, reflexiona sobre la visión crítica de Galdós con respecto a cómo eran percibidas por sus contemporáneos y por los políticos españoles decimonónicos en el momento histórico del fin del imperio colonial español.
\end{abstract}

Palabras clave: Galdós; América; Episodios nacionales; Colonias españolas

\begin{abstract}
Whereas Galdós never wrote the episode programmed Las Colonias perdidas, the reference to them and their meaning for Spanish society of the 19th century are present in the course of the Episodios nacionales as shown in this article that, in addition to signaling its location in a way, reflects on Galdós' critical view of the way in which his contemporaries and $18^{\text {th }}$ century Spanish politicians perceived the colonies at the historical moment of the end of the Spanish colonial empire.
\end{abstract}

Keywords: Galdós; América; Episodios nacionales; Spanish colonies

Galdós nunca llegó a escribir el episodio Las colonias perdidas que planeaba como octavo de la quinta serie, para el que reservaba su visión de ese fin del imperio colonial español, ${ }^{1}$ pero dejó diseminada a lo largo de numerosas páginas de los Episodios nacionales su impresión de lo que esas colonias significaron para la sociedad española del siglo XIX. En este sentido, como realizó John H. Sinningen [2002] en El amigo manso, La incógnita y Realidad, resulta de gran utilidad aplicar a España en los Episodios nacionales el esquema sugerido por Edward Said en Cultura e imperialismo [1996] con respecto a la novelística decimonónica inglesa y francesa.

\footnotetext{
1 De este hipotético episodio existe una alusión directa en Cánovas: "Mientras llega ocasión de traer a estas páginas las cosas de Cuba, ...". Cuba figura, de forma más o menos tangencial pero significativa, en los seis Episodios de la quinta serie, lo que habla del interés del autor por el tema. Pueden verse, al respecto, Julio Rodríguez Puértolas [2004, p. 263 272] y Mary Coffey [2005, p. 704-713]. Según afirma Gabriel Cabrejas [1992 p.399] con respecto a personajes de ciertas novelas, América en Galdós es un topos bidireccional: 1. Tierra de fuga y refugio $[. .$.

2. Tierra de oportunidades.
}

Las colonias españolas en general, y Cuba en particular, ocupan cierto espacio en la España reflejada por los Episodios, pero siempre de forma tangencial, porque Galdós supo captar que la metrópoli vivía de espaldas a esa realidad colonial, como si no quisiese reconocer el influjo que poseer o haber poseído tales colonias ejerció sobre ella. En buena medida, tal postura de la sociedad y la política españolas nos da el porqué de una pérdida tan poco inteligente y tan costosa en vidas humanas y recursos económicos.

Ya en la segunda serie, al novelar en 1874 el año 1815, Galdós expone la estólida actitud de Fernando VII ante la insurrección americana en una escena que muchos años después, en 1898, volverá a publicar como artículo suelto con el significativo título de "Fumándose las colonias":

$\mathrm{Su}$ Majestad estaba sentado en un sillón a poca distancia de la chimenea encendida; tenía la cabeza echada hacia atrás, de modo que miraba al techo, dirigiendo hacia él el humo de su cigarro. 
- [Explica el ministro Villamil] Fácil sería gobernar la Hacienda, si América nos enviase los tesoros que aquí nos hacen falta. Esa gran canonjía de nuestra nación no ha durado todo lo que debiera. [...] La insurrección americana exige un gran esfuerzo [...] Es preciso mandar allá un ejército; pero para esto, señor, se necesitan tres cosas: hombres, dinero y barcos.

$[,,$,

- La verdad es -dijo Fernando deteniéndose meditabundo ante la chimenea- que no estamos en Jauja.

Y luego dando un suspiro, añadió:

- Hay que despedirse de las Américas. (Memorias de un cortesano de 1815 , XXII y XXIII $y$ Vida Nueva). ${ }^{2}$

Aquí leemos ya, y nada menos que en palabras de la cabeza del Estado, la idea que permanecerá a lo largo del siglo: no importan al Rey los problemas de América ni lo que piensen o sientan sus súbditos americanos, sino el que las colonias no sigan siendo fuente de riqueza para las necesidades de la metrópoli. Las colonias son para él "esa gran canonjía de nuestra nación" que "no ha durado todo lo que debiera". Según el diccionario de la RAE, 'canonjía' significa literalmente "Prebenda por la que se pertenece al cabildo de iglesia catedral o colegial", pero, por analogía con la situación de los canónigos, su segunda acepción en español coloquial es "empleo de poco trabajo y bastante provecho", y ha pasado al uso común como sinónimo de 'sinecura' (modismo procedente del latín sine cura, literalmente "sin cuidado, sin preocupación") y de 'bicoca' o 'ganga', "cosa apreciable que se adquiere a poca costa".

En las tres series de Episodios restantes, sin pararse aparentemente en el tema colonial, se nos ofrecen numerosas pruebas de que las generaciones siguientes no fueron más prudentes ni menos corruptas que el rey Fernando y su camarilla con respecto a los restos del imperio colonial. A lo largo de las tres, encontramos pruebas de la indiferencia de los gobernantes españoles ante a los problemas coloniales. $\mathrm{Y}$ no porque los desconozcan, ya que repetidas veces se alude a ellos. Ya en 1835 un personaje advertía:

No cuente usted con las esplendideces de los que tienen su fortuna en América, en negros y caña de azúcar. A lo mejor, saldrán estos señores exaltados con la supresión de la esclavitud, y la plumada de un ministrillo dejará en cueros a más de cuatro que apalean las onzas (Mendizábal, XVII).

Sin embargo, treinta años después, solo entre varios ejemplos de la excepcional tolerancia ideológica del Ateneo de Madrid se afirma que allí, "Para que nada

\footnotetext{
2 Dado el número de ediciones de Episodios existentes, señalaré en adelante no la página, sino el capítulo en que pueden localizarse las citas.
}

faltase, había un grupo de cubanos que exponían sus ideas de autonomía y aun de emancipación de las Antillas, sin que nadie de ello se asustara" (Prim, XII). En 1870, la esclavitud sigue existiendo, y sus beneficiarios forman un grupo de presión a través del periódico El debate, que se hace:

con el dinero que han traído de Cuba don Manuel Calvo y demás negreros para hacer propaganda en favor de la esclavitud... ¿Ha visto usted cómo la Bolsa ha saludado la elección [de Amadeo de Saboya] con un alza considerable? Vea usted la mano de Manzanedo, de Herrera, de Vinent [...] El dinero cubano nos perderá... (España trágica, XXIV). ${ }^{3}$

La información se amplía en el episodio siguiente, Amadeo I, al explicar un personaje a qué obedece la boyante situación económica del periódico:

¿Sabe usted de dónde vienen los monises?... Pues vienen de Cuba... ¿Por qué abre tanto esa boca? De Cuba, sí, señor. ¿Pero usted cree que hay en España dinero que no venga de la perla de las Antillas? [...] El dinero lo mandan los ricos hacendados de la Isla para crear aquí una opinión favorable a sus intereses. [...] Los buenos españoles de allí quieren que no se precipite el Gobierno en echarles reformas y reformas. [...] Quieren los buenos españoles que si se ha de quitar la esclavitud, nos contentemos ahora con el vientre libre ${ }^{4}$ dejando lo demás para mejores tiempos. Si así no se hace, peligrará la riqueza, la propiedad, y los ingenios serán pronto montones de ruinas... Para meter estas ideas en las cabezas alocadas de acá, los hacendados desean tener aquí órganos de la opinión sensata... Ahora viene el dinero a las manos de don Manuel Calvo, que está en Madrid. [...] De las manos de Calvo pasa el dinero a las de don Adelardo Ayala, que lo distribuye... porque no es sólo El Debate el que cobra por defender la buena causa. (Amadeo I, V).

En la primavera de 1870 Prim, jefe del Gobierno Provisional, había iniciado negociaciones secretas con Estados Unidos para una posible emancipación de las Antillas, negociaciones relatadas en España trágica, y sobre las que Galdós opina por boca del personaje Segismundo:

\footnotetext{
3 Explica Rodríguez Puértolas [2004, p. 266]: “Aparte del Manuel Calvo mencionado, la lista de negreros ilustres incluía nada menos que a Francisco de Asís de Borbón, rey consorte [...]; a José Cánovas del Castillo, dirigente del Banco Español en Cuba y hermano del famoso político; a José Gener y Batet, quizá el tabaquero más poderoso de la isla. El banquero Manzanedo (canovista), el político y financiero Herrera y el aristócrata Vinent, citados, eran las cabezas madrileñas visibles en todo este entramado". Sobre el palacio madrileño de Manzanedo se dirá en el episodio siguiente que: "debía ostentar en los florones de su escudo Tabaco Virginia o Kentucky, y algunas motas de ébano, representativas de la compra y venta de negros en Cuba" (Amadeo I, III).

4 Disposición legal de 1870 que declaraba libres a los hijos de mujer esclava nacidos a partir de septiembre del 68 .
} 
en el pensamiento de Prim descubro una previsión profética, un mirar de águila que percibe lo distante mejor que lo próximo; veo el ensueño de fundar una nueva España más grande y potente, formada de pueblos ibéricos que se aglomeren y unifiquen, no con atadijos administrativos, sino con ligamento moral, filológico y étnico... (España trágica, XVII). ${ }^{5}$

Pero tales negociaciones se cortaron con el asesinato del General a finales de ese año. Nunca se aclaró el atentado aunque existen numerosos indicios de que el instigador fue el duque de Montpensier, para quien Prim suponía un obstáculo insalvable a su pretensión de reinar en España tras la revolución del 68. Pero, probablemente, hubo más grupos interesados en la desaparición del Prim, y entre ellos se señala a los colonialistas como colaboradores en el magnicidio, ${ }^{6}$ debido precisamente a ese proyecto respecto a Cuba.

Y aunque en 1873 Castelar advierte al Congreso de la República que una de las reformas imprescindibles es la abolición de la esclavitud en Cuba (De Cartago a Sagunto, VIII), según se narra casi diez años después, en 1880, los gobernantes españoles siguen sin atreverse a afrontar los problemas coloniales:

Cánovas, no atreviéndose a resolver el gran problema antillano, cedía los trastos de gobernar a quien, sobrado de valor para todo, no podía consumar la magna empresa por falta de aptitudes políticas [Sagasta]. De este modo, entre un sabio que no quiere y un valiente que no puede, decretaron para un tiempo no lejano la pérdida de las Antillas [...] Las reformas políticas de Cuba, [...] pasaron suavemente al panteón del olvido, y ni aun se trató de sacar adelante el proyecto de ley de abolición de la esclavitud que parecía lo de más urgencia (Cánovas, XVII).

En efecto, a lo largo del siglo, con un imperio reducido a Cuba y Filipinas, los gobernantes españoles más que pensar en resolver los problemas de ultramar, soñaron con nuevas aventuras coloniales. En dos momentos de la cuarta serie de Episodios, que relata el reinado de Isabel II, se ocupan sus gobernantes de América: el primero en 1862, para competir con otras ambiciones colonialistas europeas, en la intervención en

\footnotetext{
Comenta con agudeza Rodríguez Puértolas [2004, p. 264]: "Lo que los ingleses harían de modo bien inteligente ya en el siglo XX creando la Commonwealth es, según el texto, lo que Prim tenía en su cabeza con el plan cubano".

6 Pere Anguera [2014, p. 629] explica esa posible colaboración: "Prim tenía en contra en Cuba a dos importantes núcleos de presión: los partidarios de mantener la esclavitud y los de la inmovilidad del sistema colonial. Ambos temían las consecuencias de las negociaciones del General con los diplomáticos norteamericanos. En la isla se popularizó la opinión de que 'a Prim le mataron en Madrid, pero el gatillo se apretó desde La Habana",.
}

México. ${ }^{7}$ Interesa aquí a Galdós narrar el suceso histórico no por sí mismo, sino para mostrar la astucia de Prim, que conociendo la ingenuidad ambiciosa y nacionalista de Isabel II, decide retirar a sus tropas de la aventura colonial:

El ardiente españolismo de Isabel II se sublevaba y enfurecía viendo elegido para el trono de Méjico a un Príncipe austríaco, con desprecio de los españoles Príncipes. ¿Podía España tolerar tal vilipendio? No se concebían en América Majestades que no fueran de acá, de la raza y pueblo que descubrió, conquistó y civilizó, como Dios le daba a entender, aquellas doradas tierras. ¿No habían de ser españoles los soberanos de América? Pues quedárase esta con sus repúblicas, que bien españolas eran por sus dictaduras y sus pronunciamientos. Esto pensaba Isabel, y Prim supo que así pensaba (Prim, VIII).

El segundo momento surge a propósito de la expedición marítima que ocupa todo el episodio de $L a$ vuelta al mundo en la Numancia. La verdadera razón política de esta expedición de la marina española a Perú que supuso otro fracaso fue, según Galdós, la misma que había expuesto a propósito de la guerra de África en un episodio anterior, "fabricar patriotismo" para distraer al país de sus auténticos problemas. Ahora, el protagonista del episodio lo explica con mayor crudeza:

En España se dice que este furor de camorra nos lo ha pegado la Francia, nuestra vecina por el Pirineo, pues el imperio segundo que hay allí, obra de ese Luis Napoleón, nos da la moda de encender guerras con tal o cual país. La miaja de gloria que va sacando el ejército de mar y tierra, es el torniquete, como quien dice, con que los mandones trincan y aseguran a los que obedecen (La vuelta al mundo en La Numancia, XIV).

La Guerra del Pacífico relatada en este episodio sirve a Galdós para exponer la en su opinión nefasta política de España con sus excolonias, menospreciando a sus gobiernos y soñando con volver a dominarlas frente al ideal de fraternidad panhispánica que proponía el propio escritor.

\footnotetext{
Dirigida por la Francia de Napoleón III contra la entonces República mexicana de Benito Juárez, la intervención fue inicialmente apoyada por Inglaterra y España bajo pretexto de cobrar antiguas deudas; el objetivo de Napoleón fue establecer un Imperio encabezado por el príncipe Maximiliano de Austria, que acabará trágicamente dos años después: "retablo mejicano movido por el Maese Pedro de las Tullerías", apunta con sarcasmo el narrador (Prim, VIII). Galdós sigue en este tema, casi literalmente, a Ricardo Muñiz [1884, p.13-21], de quien escribe: "el verdadero confidente y corresponsal del general Prim era Muñiz, que le informaba de las menudencias políticas, por menudas importantes en esta sociedad más gobernada por la intriga que por las ideas" (Prim, VII).
} 
Un año antes de publicar este episodio, en 1905, Galdós se mostraba convencido de la existencia de ese panhispanismo en un artículo que enviaba al periódico La prensa de Buenos Aires. El artículo tenía forma de carta a Francisco Grandmontagne, un periodista que, aunque nacido en España, había marchado a la Argentina a los veintiún años y había hecho allí prácticamente toda su carrera. Extraigo algunos párrafos:

Cervantes escribió el Quijote y nosotros, los de acá y allá, constituimos el ser hispánico, vivimos, hacemos ese mismo Quijote [...]

En la geografía intelectual [El Quijote] continúa siendo el verdadero mundo nuestro donde nunca se pone el sol. Eterno día lo ilumina desde las planicies manchegas hasta las cimas de los Andes.

Los españoles (designando así, en la humana familia, a la rama de esta que habla con más o menos pureza el castellano) [...] toda la rama, que bien podríamos llamar cervántica, [...] dispersa y fraccionada, posee un lazo federativo que a unos y otros nos liga y aprieta con nudo indisoluble; este lazo, al propio tiempo signo de concordia y marca de progenie, es el idioma condensado en el poema que ha tenido y tiene más lectores en el mundo [...] Los dominios de esta creación artística se extienden desde La Mancha melancólica hasta regiones alegres y felices. La vida española, con ejércitos espirituales y el empuje de su idioma vigoroso se ha engrandecido y afirmado en lejanos territorios, poseídos en otro tiempo con dominio menos efectivo. Cabe dudar si la posesión material fue más real o más soñada que la posesión presente.

Volviendo al episodio, para poner en evidencia la equivocada política colonialista de España, Galdós crea aquí una trama novelesca que funciona como símbolo de la idea anticolonialista que quiere transmitir a sus contemporáneos. La hija de Diego Ansúrez, contramaestre de Marina retirado, se escapa con el peruano Belisario, al que Ansúrez ha rechazado como yerno por considerarlo un aventurero; Ansúrez, desesperado, vuelve a enrolarse en la Marina y embarca en la Numancia para buscarla. Pero solo la encontrará y se reconciliará con ella de regreso a Cádiz tras un largo y penoso viaje en el que sus conversaciones con diversos personajes le llevarán a cambiar de criterios. En su caso personal pues, la vuelta al mundo de la Numancia es un viaje de aprendizaje.

Si Ansúrez hubiera permitido pacíficamente la emancipación de su hija, habría mantenido su cariño, y no hubiera necesitado sufrir tantas aventuras hasta encontrarla. También España, parece decirnos Galdós con esta especie de parábola, se hubiera ahorrado muchos sinsabores y hubiera mantenido el respeto y el cariño de sus excolonias, si hubiera reconocido desde el primer momento el derecho de los pueblos a emanciparse.

El episodio sirve también a Galdós para contrastar el rechazo de los excolonos hacia lo español -"La cordialidad y el agasajo entre naturales y forasteros no existían en aquellos días"-, con la enorme huella cultural dejada por la antigua metrópoli en Hispanoamérica:

Los oficiales españoles recorrían con actividad un poco melancólica la Ciudad de los Reyes. La sombra de Pizarro les acompañaba; las remembranzas de la patria salían a recibirles en las fachadas de los edificios de la época vicerreal. A cada instante surgía la anagnórisis, o sea el descubrimiento y declaración de parentesco. [...] Nuestro, de casa, de familia, era el rostro de aquel monumento; nuestra también el alma, el interior, impregnado de dulce misterio y de místico encanto. Igual impresión de parentesco les daba el palacio de los virreyes, hogaño presidencial. ¿Pero estaban en la América del Sur, o en Ronda, Tarifa o Algeciras? ( $L a$ vuelta al mundo en La Numancia, XIV).

Y esa huella es mutua. Algunas alusiones menores que atañen a cuestiones lingüísticas, geográficas, de decoración o de gastronomía, repartidas por distintos Episodios, nos indican hasta que punto la vida peninsular estaba impregnada de notas coloniales:

- Para ejemplificar el rebuscamiento lingüístico publicitario se dice que "Publicistas que pasaron por excelentes llamaban [...] a La Habana la virgen de los trópicos" (Bodas reales, XV). En el lenguaje conversacional, Felipa, da "lo que llaman en Cuba un boca-abajo" (Amadeo I, VI), es decir, un azote en el trasero. Tito relata que "En la noche social resplandecía la luciérnaga" del "grande ingenio" de Ramón Correa, periodista de El Debate, y aclara: "Por ser Correa cubano, debo decir cucuyo" (Amadeo I, XI), o sea, "coleóptero caribeño cuyas alas brillan en la oscuridad'; el mismo Tito califica la historia política de los años 1873-74 con la voz amerindia "manigua" ( $L a$ primera república, I y XXIX), lo que significa 'bosque tropical impenetrable'.

- Los conocimientos geográficos se muestran a menudo en relación con las colonias; así, para mostrar la ignorancia de los gobernantes, escribe la Incógnita a Calpena: "hay ministros que creen que La Habana es camino de Filipinas" (De Oñate a La Granja, III); un personaje popular asegura que "La Hunguería y la tierra de los austriacos no son lo mismo, pues la una linda con las Américas, y la otra es propiamente como una familia real" (Las tormentas del 48, XXIV); y sobre la escasa 
educación recibida por Virginia y Valeria, afirma Beramendi:

Todo lo que saben de geografía no vale un comino: se reduce a nociones vagas de la superficie del planeta, y al conocimiento de que es forzoso embarcarse para ir a las Américas descubiertas por Colón (La revolución de julio, III).

- En decoración, parece sugerirse que el mobiliario colonial está muy presente en las casas españolas; así, al describir la estancia en que don Wifredo corre su juerga, comenta el narrador: "decorada con un lujo chillón y barato, había muebles de algún valor; otros, sin que nadie se lo preguntara, declaraban haber venido de las Américas" (España sin rey, IX).

La utilización de algunas colonias como penal para delitos comunes asoma en la cuarta serie, a través de los Ansúrez:

al mayor, que se llama como yo, lo tenemos en Ceuta, por un achaque...

-¿Llama usted achaques a los crímenes?

-Por una mala querencia, señor. Acciones hay malas que son nacidas del mucho querer (Narváez, V).

Coge la policía al desdichado Ansúrez, y por el doble delito de robar a Virginia y del desacato reciente a la autoridad, me le mandan a Leganés atado codo con codo. De allí, sin dejarle respirar, sin que nadie se entere, ni puedan socorrerle los que le aman, saldrá para Filipinas o para Fernando Poo en la primera cuerda... (O’Donnell, XVI)

Y tal uso se multiplica si se trata de motivos políticos. Con Narváez las deportaciones son constantes, pero figuran también con gobernantes de signo diverso, como el conservador Istúriz o el liberal Sagasta. En 1848, con Istúriz, el infeliz Faustino Cuadrado "movido del hambre más que del furor político, tuvo platónica participación en la trifulca de mayo [...] Ya está en camino para el embarque. ¡A Filipinas, Señor!” (Las tormentas del 48, XXXI); al año siguiente, "Narváez, no cesaba en los envíos de deportados a Filipinas" (Narváez, II); el propio general afirma que el periodista Correa "ha estado en un tris que le mandemos a Filipinas" por progresista (Narváez, XIV); furioso por la ultramontana conspiración del "Ministerio relámpago" (1849), también explica:

Es gran injusticia mandar a Filipinas a tanto infeliz descamisado, y dejar aquí a los revoltosos de buena posición [...] no quisiera morirme sin coger un barco viejo, $[\ldots]$ y llenarlo de estas beatas... y mandarlo bien abarrotado de ellas... ¿Qué Canarias ni qué Filipinas?... ¡a las islas Marianas!" (Narváez, XV).
Bravata de la que algo después vemos reírse en las amenazadas:

¿Con que a las islas Marianas nada menos? ¿Está él bien seguro de que no le embarcarán para allá con viento fresco? Si en aquellas islas hay caribes, iqué buen maestro se pierden para perfeccionarse en la barbarie!"' (Narváez, XVIII),

Ya en 1874, iniciada la Restauración, Leona evoca los últimos tiempos de la República:

Al gobierno de Sagasta no le llegaba la camisa al cuerpo y se defendía deportando a Filipinas a todos los que juzgaba sospechosos. Sospechoso era el país entero, que pedía orden y paz, metiendo de una vez en cintura a los malditos carcas y a los insurgentes de Cuba (Cánovas, II).

Los Episodios muestran también como muy diversos militares españoles han hecho parte de su carrera en las colonias. En primer lugar, Espartero y Maroto, cuyo entendimiento para terminar la primera guerra carlista se debe en parte a haber luchado juntos en América contra los independentistas. El pretendiente carlista desconfía de los "planes maquiavélicos de los dos Generales compañeros en las revoluciones de América" (VERGARA, XXXVIII). Terminada la guerra, durante la regencia de Espartero, sus seguidores serán llamados despectivamente "ayacuchos", en recuerdo de la derrota de Ayacucho (1824) que significó el final definitivo del dominio colonial español en América del Sur. En segundo lugar, militares menos célebres como Valdés, jefe del ejército del Norte en Zumalacárregui, o Hidalgo, mariscal de campo y Nicolás Estévanez en Amadeo I han prestado servicio en las colonias; la trayectoria de este último nos permite conocer la brutalidad del ejercito español en Cuba: en enero de 1871 se fusila a varios estudiantes de Medicina en La Habana por molestar a los Voluntarios. El histórico Estévanez, que abandona el ejército a causa de este suceso, concluye de su relato:

por un lado los enemigos de la patria, por otro los que, llamándose hijos de ella la deshonran con sus violencias y crueldades: imposible residir en Cuba sin tirar el uniforme o tirarse al mar (Amadeo I, IX).

Pero no son solo los militares quienes abusan de la colonia. Los Episodios nos ofrecen algunos ejemplos de florecientes negocios poco limpios a partir de la riqueza proveniente de Cuba: así, en 1854 un periódico crítico, El Murciélago, "truena" contra "la concesión a la casa Sangróniz de un servicio de vapores para La Habana" (La revolución de julio, XI), y en el siguiente episodio, se habla a Teresa Villaescusa de 
un opulento señor [que] tiene la contrata de todo el tabaco que en España se consume, y que no sabe qué hacer del dinero [...] Es de estos hombres que de chicos se van descalzos a la Habana y vuelven con las botas puestas... Pero este no trabajó en calzado, sino en sombreros, con más suerte que mi difunto esposo, que después de ganar en Cuba muchísimo dinero, allá se dejó las onzas y la pelleja... (O’Donnell, XXIX). ${ }^{8}$

Las alusiones más numerosas a Cuba, y también las más reveladoras para lo que pretendo defender aquí, son aquellas que ofrecen la visión generalizada que en España se tiene sobre la colonia, no como una provincia más del país, lo que oficialmente era, ni como una fuente de riqueza a la que es necesario proteger, sino como una salida para quienes quieren enriquecerse con facilidad o tienen problemas de cualquier tipo en la Península. En este sentido, la visión de Galdós sobre el colonialismo español coincide en gran medida con lo explicado por Edward Said [1996, p. 118] a propósito del imperialismo inglés y francés reflejado en sus respectivas novelísticas:

Durante la mayor parte del siglo XIX europeo el imperio funciona como punto de referencia, punto de definición y sitio fácilmente aceptado para viajar, y para obtener riqueza y servicio: es una presencia codificada, aunque solo en parte visible, similar a los criados de las grandes mansiones y hoteles [...] los hechos del imperio se asocian con incrementos de fortuna $[\ldots]$. Los descarriados hijos menores eran enviados a las colonias, los parientes mayores e impresentables marchaban para tratar de recuperar patrimonios perdidos [...] Los territorios coloniales han sido esferas de posibilidad y han estado siempre asociados a la novela realista.

En los Episodios, algunos personajes buscan de forma honrada su mejoría económica en las colonias, como Valentín Arratia, piloto de altura que "había pasado lo mejor de su vida rompiendo mares en América" (Luchana, XV), o como Santiago Ibero hijo que en 1862 pretende encontrar la gloria enrolándose en la expedición a México del general (Prim, I); ninguno de los dos tendrá suerte, lo que sí encuentra Mendaro emigrante que, en $L a$ vuelta al mundo en la Numancia, es dueño de una próspera pulpería en Chile en 1866 (III). Pero para la mayoría, las colonias son un instrumento de escape a su mala situación personal, familiar, económica, social, judicial o política. Ya en 1807, se rumorea que ante el terror que les produce el motín de Aranjuez, los reyes Carlos IV y María Luisa de Parma, proyectan huir a América (La corte de Carlos IV, VII). Pero sobre todo las tres últimas series, que novelan la historia de España desde 1834 a 1880, están

\footnotetext{
8 En la versión que Galdós eliminó del manuscrito se añadía "Si sabrá el hombre ganar[1o] que a La Habana fue de sombrerero y volvió de capitalista".
}

salpicadas de personajes de mayor o menor entidad que buscan en las colonias remedio a sus males. En 1837, de cierto personaje muy secundario -lo que muestra el interés del autor por mostrar rasgos de la sociedad de la época, aunque sean innecesarios para el argumento- se afirma:

va a La Habana con un buen destino, creo que en Aduanas o en Rentas, de lo que me alegro infinito, a ver si levanta cabeza y puede socorrer a sus padres, que están en la miseria por sostenerle aquí (La estafeta romántica, XI).

Más de 15 años después, en 1853, intenta marchar Gracián a América no por dificultades económicas, sino para eludir problemas con la justicia, y conseguir así "el indulto, la rehabilitación y un ascenso, dos con pase a Cuba" (Los duendes de la camarilla, XXVIII). Varios personajes desean aprovecharse de la existencia de las cárceles coloniales por motivos privados, como aparenta Domiciana en 1850 para librar de inquietudes amorosas a Lucila: “¿Pero cuándo [...] lo prenden y se lo llevan a Filipinas, para que descanses tú y descansemos todos?" (Los duendes de la camarilla, IV). Y algo similar intenta, ya en la República, la extravagante Chilivistra: quiere salvar de la pena capital a su marido maltratador y carlista, pero "que le mandaran lejos, lejos, a Filipinas por ejemplo, poniendo así la mayor distancia posible entre el adorable cuerpo de la señora y la mano impía del esposo" (De Cartago a Sagunto, VII).

Las colonias resultan útiles a personajes descarriados; así, Beramendi aconseja a Guillermo de Aransis, joven rico arruinado con el juego y perseguido por sus acreedores, marchar a América:

Mira las cosas por el lado práctico, que suele ser el lado más bonito; no desprecies los ingenios, los potreros y cafetales que para ti reserva la virgen América; [... considera los cientos de miles de cajas de azúcar que podrás verter en el océano de tus amarguras para endulzarlo... (O'Donnell, X).

Y Valeria en 1856 pretende librarse de su marido, jugador que está dilapidando su hacienda, buscándole un destino colonial:

No había más que un medio: mandarle a Filipinas, con lo cual ella se veía libre de él, y él cortaba por lo sano la insostenible situación a que le habían llevado sus estúpidos vicios.

Iniciado el proyecto por la esposa, el marido lo encontró de perlas. Quería pasarse por agua, y salir a un mundo nuevo donde no le conocieran. [...]. A principios de abril recibió Navascués el pase a Filipinas, con ascenso, $[\ldots]$ iQué descansada se quedó la pobre! (O’Donnell, IV). 
En 1870, el sacerdote Andrés de Romeral para poder vivir con su amada se hace protestante y "se irá uno de estos días a Gibraltar con su coima. Allí se casarán, y luego... América es grande... Las paletadas de la hélice de los vapores, pim, pam, cantan: '¡Libertad, libertad!'”. En ese mismo año, Enrique Bravo proyecta marcharse a Cuba como única salida a su complicada situación política:

\begin{abstract}
Aunque no siento ganas de pasar el charco, quizás me convenga alejar de Madrid todo lo posible este oprobio que me han traído mis desgracias... Querido Vicente, estoy pasando amarguras de que tú, el mimado de la suerte, no puedes tener idea. Ya no entro en ningún café, ya no voy al teatro... El temor de encontrar amigos que me zahieran o me insulten, me retrae de la sociedad que siempre fue más de mi gusto... (España trágica, XXII).
\end{abstract}

Quien en 1871 informa a Tito sobre el dinero que recibe El Debate había sido "mozo de café o de fonda, que se fue a La Habana y de allá volvió dándoselas de ricachón, o siéndolo de verdad" (Amadeo I, V)

No para todo el mundo las colonias son signo de fortuna, según se consigna sobre alguien en 1835: "se fue a la Habana en tiempo del general Tacón, y murió de mala manera bajo el mando de Roncali. Apenas ha dejado rastro de sí" (Mendizábal, II), pero el diario de Beramendi de 1853 transparenta que en la época una de las posibilidades para salir de la pobreza, equiparable a otros medios fortuitos, era heredar de quien se hubiese enriquecido en las colonias: "No ha de faltar un buen negocio, un repentino hallazgo de veta minera, un cambio político, un premio de lotería, una herencia de tíos de América" (La revolución de julio, VI).

En resumen, para los españoles de la época, las colonias solucionan todo tipo de problemas como fuente casi inagotable de cuya conservación es innecesario preocuparse. Cierto que esa fue la visión de todas las potencias coloniales, pero también lo es que todas acabaron perdiendo sus imperios. El marqués de Beramendi, personaje poco escrupuloso y con profundo conocimiento de la sociedad isabelina que le tocó vivir, lo explica con claridad no exenta de cinismo, al aconsejar al Guillermo de Aransis, perseguido por sus acreedores:

en España tenemos un medio seguro de aliviar la desgracia de los que por su mala cabeza, por sus vicios o por otra causa, pierden su hacienda. Se les manda a la isla de Cuba con un buen destino, y allá se arreglan para recobrar lo que aquí se les fue entre los dedos. España goza de esta ventaja sobre los demás países: posee un heroico bálsamo ultramarino para los males de la patria europea... (O'Donnell, VIII).
Y se continúa pensando igual, casi veinte años más tarde, según repite Vicente a Enrique Bravo, otro amigo con poblemas:

En España tenemos un singular rocío de olvido, que desciende benéficamente del cielo sobre las inconsecuencias políticas, y las hace desaparecer sin que quede rastro de ellas... (España trágica, XXVII).

"Canonjía", "bálsamo", "rocío del olvido", son las denominaciones que oímos a varios españoles de diferentes situaciones sociales y en momentos diversos del siglo para referirse a lo que consideran "sus posesiones" americanas. En este sentido, el mensaje que a mi entender se desprende de los Episodios con respecto a las colonias, es que los políticos españoles decimonónicos no hicieron más que seguir el camino suicida que la propia sociedad civil les marcaba.

\section{Referencias}

ANGUERA, Pere. El general Prim. Biografía de un conspirador. Barcelona: Edhasa, 2014

CABREJAS, Gabriel. "Spain go home". Pensamientos intempestivos sobre el tema de América en Galdós. Thesaurus, v. XLVII, n. 2, p. 397-404, 1992.

COFFEY, Mary. Las colonias perdidas: un episodio nacional que no escribió Galdós. In: CONGRESO INTERNACIONAL GALDOSIANO, VII., 2005, Las Palmas. Anales... Las Palmas: Cabildo Insular de Gran Canaria, 2005. p. 704-713.

MUÑIZ, Ricardo. Apuntes históricos sobre la revolución de 1868. Madrid: Imprenta de Fortanet, 1894. Tomo I.

PÉREZ GALDÓS, Benito. Una carta sobre El Quijote. Buenos Aires: La Prensa, 1995.

PÉREZ GALDÓS, Benito. Fumándose las colonias. Madrid: Vida Nueva, 1989. p. 16-17.

PÉREZ GALDÓS, Benito. Episodios nacionales. Segunda serie. La España de Fernando VII. Ed. de D. Troncoso. Barcelona: Destino, 2006.

PÉREZ GALDÓS, Benito. Episodios nacionales. Tercera serie. Cristinos y carlistas. Ed. de D. Troncoso. Barcelona: Destino, 2007.

PÉREZ GALDÓS, Benito. Episodios nacionales. Cuarta serie. La era isabelina. Ed. de D. Troncoso. Barcelona: Destino, 2009.

PÉREZ GALDÓS, Benito. Episodios nacionales. Quinta serie. Revolución y Restauración. Ed. de D. Troncoso. Barcelona: Destino, 2010.

RODRÍGUEZ PUÉRTOLAS, Julio. Cuba en la última serie de los Episodios nacionales de Galdós. In: Donatella Ferro. Roma: Bulzoni Editore, 2004. p. 263-272.

SAID, Edward. Cultura e imperialismo. Barcelona: Anagrama, 1996. 
SINNINGEN, J. H. Un signo cambiante: Cuba en Galdós y en nuestros tiempos. In: Morada de la palabra. San Juan: Universidad de Puerto Rico, 2002. Vol. II, p. 1553-1565.

Recebido: 20 de abril de 2017

Aprovado: 20 de junho de 2017

Contato:

Dolores Troncoso Durán < dtroncoso@uvigo.es $>$ 